\title{
Performance Estimation of Organic Rankine Cycle by Using Soft Computing Technics
}

\author{
Tuğba Kovact ${ }^{a}$, Arzu Şencan Şahin ${ }^{b *}$,Erkan Dikmen ${ }^{c}$, Hasan Burak Şavkll ${ }^{d}$ \\ Süleyman Demirel University, Technology Faculty, 32260, Isparta, TURKEY \\ *E-mail address: arzusencan@sdu.edu.tr \\ ORCID numbers of authors:

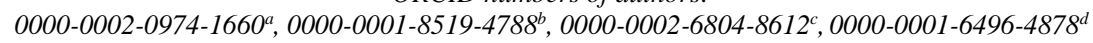

Received date: March 2017

Accepted date: May 2017

\begin{abstract}
In this study, the thermal efficiency values of Organic Rankine cycle system were estimated depending on the condenser temperature and the evaporator temperatures values by adaptive network fuzzy interference system (ANFIS) and artificial neural networks system (ANN). Organic Rankine cycle (ORC) fluids of R365-mfc and SES32 were chosen to evaluate as the system fluid. The performance values of ANN and ANFIS models are compared with actual values. The R2 values are determined between 0.97 and 0.99 for SES36 and R365-mfc, and this is satisfactory. Although it was observed that both ANN and ANFIS models obtained a good statistical prediction performance through coefficient of determination variance, the accuracies of ANN predictions were usually better than those of ANFIS predictions.
\end{abstract}

Keywords: Adaptive network fuzzy interference system, artificial neural networks system, Organic Rankine cycle, R365-mfc, SES36

\section{Introduction}

In a world where refrigerants used, the environmental factors of these fluids should also be considered. Ozone depletion potential (ODP) of a chemical compound can cause to degradation to the ozone layer. Global warming potential (GWP) is a measure of how much a given different gas contributes to global warming effects. It assigns a value to the amount of heat trapped by greenhouse gas to the amount of heat trapped by a similar mass of carbon dioxide over a specific period of time. The GWP of carbon dioxide is definition ' 1 ' by the Intergovernmental Panel on Climate Change. GWP should not be used as the sole measure. If lower GWP value refrigerant is used, then it may be by increased energy consumption [1]. For optimal system design consider the economic factor, a ratio of power out to total heat transfer is selected as system performance. Sometimes there is a contradiction between the safety and the environmental protection indicator [2]. In this study, R365-mfc and SES36 are chosen as 
the working fluids. Important some thermodynamic properties of these fluids are given at Table 1.

Table 1.Thermodynamic and environmental properties of R365-mfc and SES36 [3]

\begin{tabular}{|c|c|c|}
\hline Parameter & R365-mfc & SES36 \\
\hline Formula & $\mathrm{CF}_{3} \mathrm{CH}_{2} \mathrm{CF}_{2} \mathrm{CH}_{3}$ & $\mathrm{CF}_{3} \mathrm{CH}_{2} \mathrm{CF}_{2} \mathrm{CH}_{3}+\mathrm{PFPE}$ \\
\hline Molecular weight $\left(\mathrm{kg} \mathrm{kmol}^{-1}\right)$ & 148,1 & 184,85 \\
\hline Boiling point at $1.013 \mathrm{bar}\left({ }^{\circ} \mathrm{C}\right)$ & 41,3 & 35,6 \\
\hline Critical temperature $\left({ }^{\circ} \mathrm{C}\right)$ & 186,9 & 177,6 \\
\hline Critical pressure (bar) & 32,5 & 28,5 \\
\hline $\begin{array}{l}\text { Ozone Depletion Potential, ODP (\% by } \\
\text { weight) }\end{array}$ & 0 & 0 \\
\hline $\begin{array}{l}\text { Global Warming Potential, GWP100 (\% by } \\
\text { weight) }\end{array}$ & 825 & - \\
\hline
\end{tabular}

For R-365mfc, the uncertainty in the speeds of sound is $0.05 \%$, in heat capacities is $2 \%$, in vapor pressures is $0.25 \%$ at temperatures $280 \mathrm{~K}$ and $360 \mathrm{~K}$. In the critical region of fluid, the uncertainties are higher for all properties [4]. SES36 has a wide compatibility range with many common materials. SES36 could be alternative to the hydrocarbons because of its particular characteristics: high molecular mass, non-flammable, chemically stable, compatible with the most construction materials and environmentally fluid $[5,6]$.

Globally, role of the efficient energy is significant and critical, particularly in cooling processes. Organic Rankine Cycle (ORC) is an energy conversion technology using low grade heat source due to its distinctive thermodynamic performance. The ORC is a suitable technology even for low temperatures below $100^{\circ} \mathrm{C}$. A selection of the working fluids is very important parameter for the performance improvement. Compared to other heat engine cycles other systems, the ORC is better than them. ORC is used high waste energy utilization compared with other systems, and the cost of ORC is cheaper than the others. Furthermore the dry working fluids are more suitable for organic Rankine cycle system [7, 8]. Many of researchers who have investigated the performance of ORCs are such as Kosmadakis et al. [9], Braimakis et al. [10]. Kosmadakis et al. [9] is presented the detailed trial investigation of an ORC, which is planned to operate at supercritical conditions. Braimakis et al. [10] is investigated the waste heat recovery potential of the ORC and some of its innovative variations. Five natural refrigerants and their binary mixtures were evaluated as working fluids for a waste heat recovery ORC. A positive correlation between the heat source temperature of the fluids and their critical temperature was observed.

Fundamental equations used in ORC efficiency calculation are given as follows [11]:

$$
\begin{gathered}
W_{p}=\dot{m}\left(h_{2}-h_{1}\right) \\
Q_{B}=\dot{m}\left(h_{3}-h_{2}\right) \\
W_{t}=\dot{m}\left(h_{4}-h_{3}\right) \\
Q_{c}=\dot{m}\left(h_{4}-h_{1}\right) \\
\eta=\frac{W_{t}-W_{p}}{Q_{\theta}}
\end{gathered}
$$


where $\mathrm{W}_{\mathrm{p}}$ is the work in the pump, $\mathrm{Q}_{\mathrm{E}}$ is the heat transfer rate into the evaporator, $\mathrm{W}_{\mathrm{t}}$ is the work produced in the turbine, $Q_{C}$ is the heat transfer rate in the condenser, $\eta$ is the thermal efficiency of the ORC, $\mathrm{h}$ is the enthalpy, $\mathrm{m}$ indicates the mass flow rate of the working fluid. Each component is accepted as a steady-state steady-flow system. A basic Rankine cycle is given at Fig. 1.

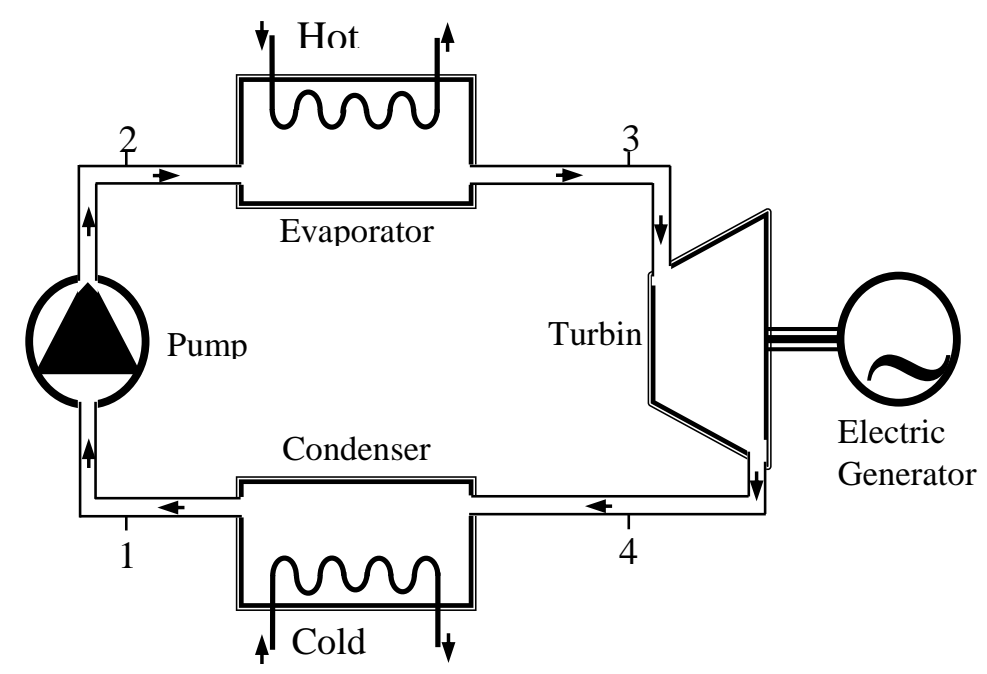

Fig. 1. Simple organic Rankine cycle (ORC)

Roy et al. [1] compared second law efficiency, irreversibility, work out, mass flow rate with increase in turbine inlet temperature of an ORC with superheating under different heat source temperature conditions. Among the refrigerant examined, R-123 produced maximum efficiencies and minimum irreversibility. The performance of investigated non-regenerative ORC during super heating using fluids R-134a and fluid R-12 is R-12 may be replaced by R$134 \mathrm{a}$ without much affecting the considered system performance.

An important aspect of ORC is choosing of the refrigerant. A wide variety of organic refrigerant could be used in ORC. The refrigerants were determined to occur chemical deterioration at high temperature and pressure. The critical pressures of these fluids are low. Therefore, the ORC systems using with these refrigerants must be operated to close temperature range and low pressure. In this regard, organic Rankine cycle fluids of R365-mfc and SES32 were chosen to evaluate as the system fluid. Kim et al. [12] carried out performance evaluation of an organic Rankine cycle system using low-grade heat at temperatures. The findings of this study highlight the feasibility of an ORC system that uses low-grade heat at a temperature below the boiling point. Li et al. [13] analyzed the effect of liquid-separated condensation on the ORC performance. Zhang et al. [14] carried out performance evaluation of organic Rankine cycle systems utilizing low grade energy at different temperature. Javanshir and Sarunac [15] analyzed thermal efficiency and net power output of a simple subcritical and super critical Organic Rankine Cycle. Efficiency of an ORC operating with isentropic working fluids is higher compared to the dry and wet fluids, and working fluids with higher specific heat capacity provide higher cycle net power output.

In recent years, there are extensive research in the artificial intelligence and soft computing methods for estimation properties of energy systems. Refrigeration system with two-stage and intercooler were optimized using fuzzy logic and genetic algorithm by Kılıç [16]. As a result, optimum working condition of system was estimated by the genetic algorithm as $-6.0449^{\circ} \mathrm{C}$ 
for evaporator temperature, $25.0115^{\circ} \mathrm{C}$ for condenser temperature and 5.9666 for COP. Köse and Mühürcü carried out control of non-linear chaotic system including noise using genetic based algorithm [17]. Kılıç made an application artificial neural network to estimation the coefficient of performance in the transcritical $\mathrm{CO}_{2}$ one-stage vapor compression cycles. The results of the ANN are compared with the actual data [18]. When considering the benefits, more work needs to be done on ORC systems estimated by network systems. In this study, the thermal efficiency of ORC system operating with R365-mfc and SES36 refrigerants by using an artificial neural network and adaptive network-based fuzzy inference system models are estimated. The results of this study will help to obtain a very accurate and fast forecast of the thermal efficiency of ORC system.

\section{Materials and Methods}

Artificial neural Networks (ANN) are developed application technique based on the human brain by imitated using silicon and wires as neural system. The neurons connected by weights. Neural networks are organized in layers. Patterns are introduced to the network with the input layer, which communicates to one or more hidden layers. Each neuron applied an activation function to assign the output signal. The adaptive network-based fuzzy inference system (ANFIS) is ANN and fuzzy logic (FL). Fundamentally, five layers are used to constitute a system. From nodes and directional links consist of ANFIS is a multilayer network based on fuzzy inference system. It has learning capability to nonlinear functions. ANFIS and ANN methods for different engineering applications were used in literature [19-21].

The thermal efficiency values of ORC depending on the evaporator temperature $\left(\mathrm{T}_{\mathrm{E}}\right)$, condenser temperature $\left(\mathrm{T}_{\mathrm{C}}\right)$ for R365-mfc and SES36 refrigerants is estimated by using ANN and ANFIS. In this architecture, while evaporator temperature $\left(\mathrm{T}_{\mathrm{E}}\right)$ and condenser temperature $\left(\mathrm{T}_{\mathrm{C}}\right)$ were used as input value, the thermal efficiency value was used as output data. The data set of ANN models is important to estimate accuracy of the model. Therefore, sufficient amount of data in a wide range should be entered as input data. In this regard, sufficient data are used in models were distinguish for training data. To compare with actual values were modeled at different temperature values range about $20-40^{\circ} \mathrm{C}$ at condenser temperatures and $50-90^{\circ} \mathrm{C}$ at generator temperatures.

In this study, ANN structure is constructed using two-layer feed forward neural network models with two input layers and one output layers and test run with the available input data. The ANN model developed the Levenberg-Marquardt (LM) algorithm. A tan-sigmoid activation function was used for the hidden and output layer. The developing of the algorithm was the determination of certain amount of neurons in the hidden layer. After output data is compared with the other results, the iteration process is finished and the closest estimate is obtained. There are various studies focusing on ANN at theoretically, such as Shojaeefard et al. [22], Li et al. [23]. A diagram of a multilayer feed forward neural network model structure used in this study is shown in Fig. 2. 


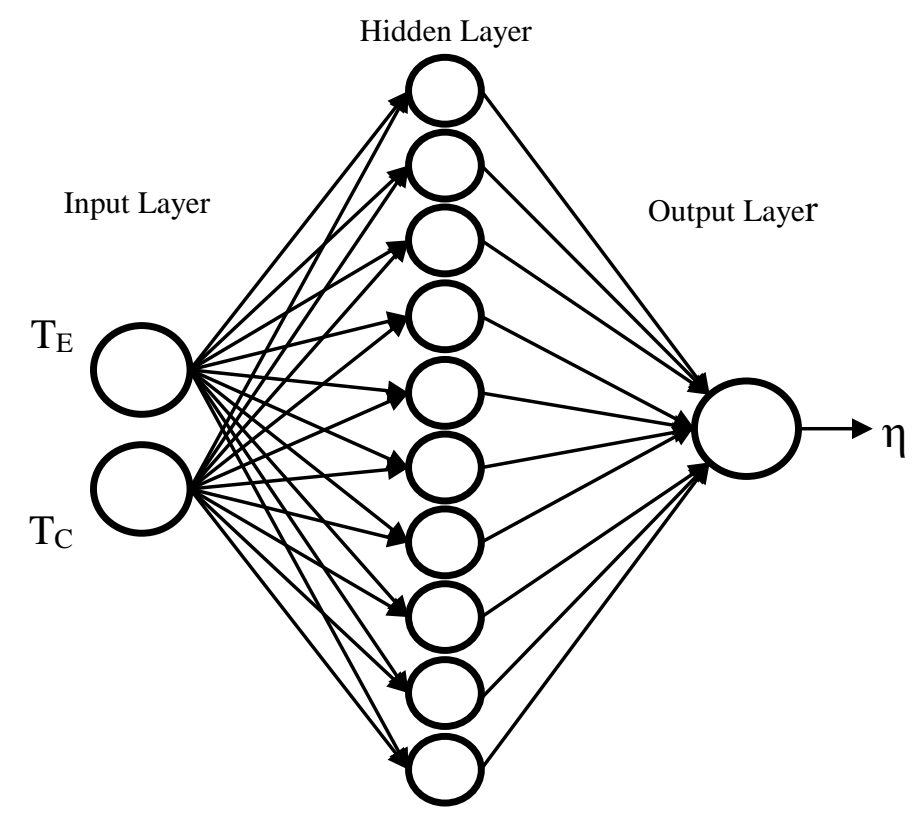

Fig. 2. ANN architecture

Appropriate ANFIS structure for the thermal efficiency of ORC system is estimated using hybrid learning rule. The functions were used in the ANFIS model at given Table 2.

Table 2. ANFIS architecture and training parameters

\begin{tabular}{lcc}
\hline & R365-mfc & SES36 \\
\hline Number of training data & 54 & 54 \\
Type of MF & Gaussmf & trimf \\
Number of fuzzy rules & 81 & 81 \\
Learning rules & Least square estimation & Least square estimation \\
Momentum constant & 1,25 & 1,25 \\
Number of epoch & 1000 & 100 \\
\hline
\end{tabular}

Determining ANN and ANFIS models were trained with obtained data and a suitable model was designed. $\mathrm{R}^{2}$ and correlation values obtained from the completed training results were much closed ' 1 '. The ANN and ANFIS modeling results are satisfactory.

\section{Results and Discussion}

In this study, the thermal efficiency of ORC system operating with R365-mfc and SES36 was predicted by using the ANFIS and ANN approaches. Temperature values like evaporator temperature and condenser temperature was used as input parameter. The results of different models were compared.

The thermal efficiency value of ORC systems depends firstly on the temperatures of the evaporator and the condenser. Mago et al. [24] presented organic refrigerant need not be superheated as the thermal efficiency ratio remains constant when the inlet temperature of turbine is increased. Furthermore, superheating organic refrigerants increase the irreversibility in the second law analysis. 
The performance of ANN and ANFIS model were assessed by comparing the actual value. The coefficient of multiple determination $\left(\mathrm{R}^{2}\right)$, the root mean square (RMS) and the coefficient of variation (cov) values were presented a comparison statistically, and the results are given at Table 3. As obtained are very close to 1, and this is satisfactory. Although it was observed that both ANN and ANFIS models obtained a good statistical prediction performance through coefficient of determination variance, the accuracies of ANN predictions were usually imperceptible better than those of ANFIS predictions.

Table 3. Comparison of statistical measures between ANN and ANFIS technique for thermal efficiency values estimation of ORC system

\begin{tabular}{llcccccc}
\hline & & \multicolumn{3}{c}{ SES-36 } & \multicolumn{3}{c}{$\mathrm{R}-365 \mathrm{mfc}$} \\
\cline { 3 - 8 } & Method & $\mathrm{R}^{2}$ & $\mathrm{RMS}$ & cov & $\mathrm{R}^{2}$ & RMS & cov \\
\hline Efficiency & ANFIS & 0,985973 & 0,012043 & 0,121438 & 0,974897 & 0,015232 & 0,164669 \\
ratio & ANN & 0,998546 & 0,003877 & 0,039095 & 0,987338 & 0,010818 & 0,116951 \\
\hline
\end{tabular}

The error is determined by RMSE defined as:

$$
R M S E=\sqrt{\frac{\sum_{m=1}^{n}\left(y_{p}-t_{m}\right)^{2}}{n}}
$$

The $\mathrm{R}^{2}$ and the cov values are defined as:

$$
\begin{gathered}
R^{2}=1-\frac{\sum_{m=1}^{n}\left(t_{m}-y_{p}\right)^{2}}{\sum_{m=1}^{n}\left(t_{m}-\bar{t}_{m}\right)^{2}} \\
\operatorname{cov}=\frac{R M S}{\left|\bar{t}_{m}\right|} 100
\end{gathered}
$$

where $\mathrm{n}$ is the number of data patterns, $\mathrm{y}_{\mathrm{p}}$ is the predicted, $\mathrm{t}_{\mathrm{m}}$ is the measured value of one data point $\mathrm{m}$, and $\bar{t}_{m}$ is the mean value of all measure data points.

Comparison the actual value with the results obtained from models of R365-mfc by ANN and ANFIS approaches are shown in Figure 3 and 4. As shown from these figures, the curves of estimated values were determined to be much closed to curve of actual value, the differences are very minimal. Despite both of these models to achieve good results, ANFIS model was shown to be much more successful results for evaporator temperature. As is shown in Fig. 3, thermal efficiency values with the increasing of evaporator temperature increased. It can be seen in Fig. 4 that the thermal efficiency of an ORC system with R365-mfc decreases when condenser temperature increases. Similar results have been found in Y1lmaz et al.[11].

Comparison the actual value with the results obtained from models SES36 by ANN and ANFIS approaches are shown in Figure 5 and 6 . When the plot of the relationship between generator temperature and efficiency ratio is viewed, it seems that the curves of the actual values, the ANN and the ANFIS estimates are very close to each other. For both fluids, the efficiency was increased in proportion to the evaporator temperatures and changed inversely 
proportional to the condenser temperatures. Thermal efficiency variations for ORC system operating with SES36 are similar thermal efficiency variations for ORC system operating with R365-mfc. In Fig. 5 it can be observed that the thermal efficiency of ORC system operating increases with evaporator temperature. It can be seen in Fig. 6 that the thermal efficiency of ORC system decreases when condenser temperature increases.

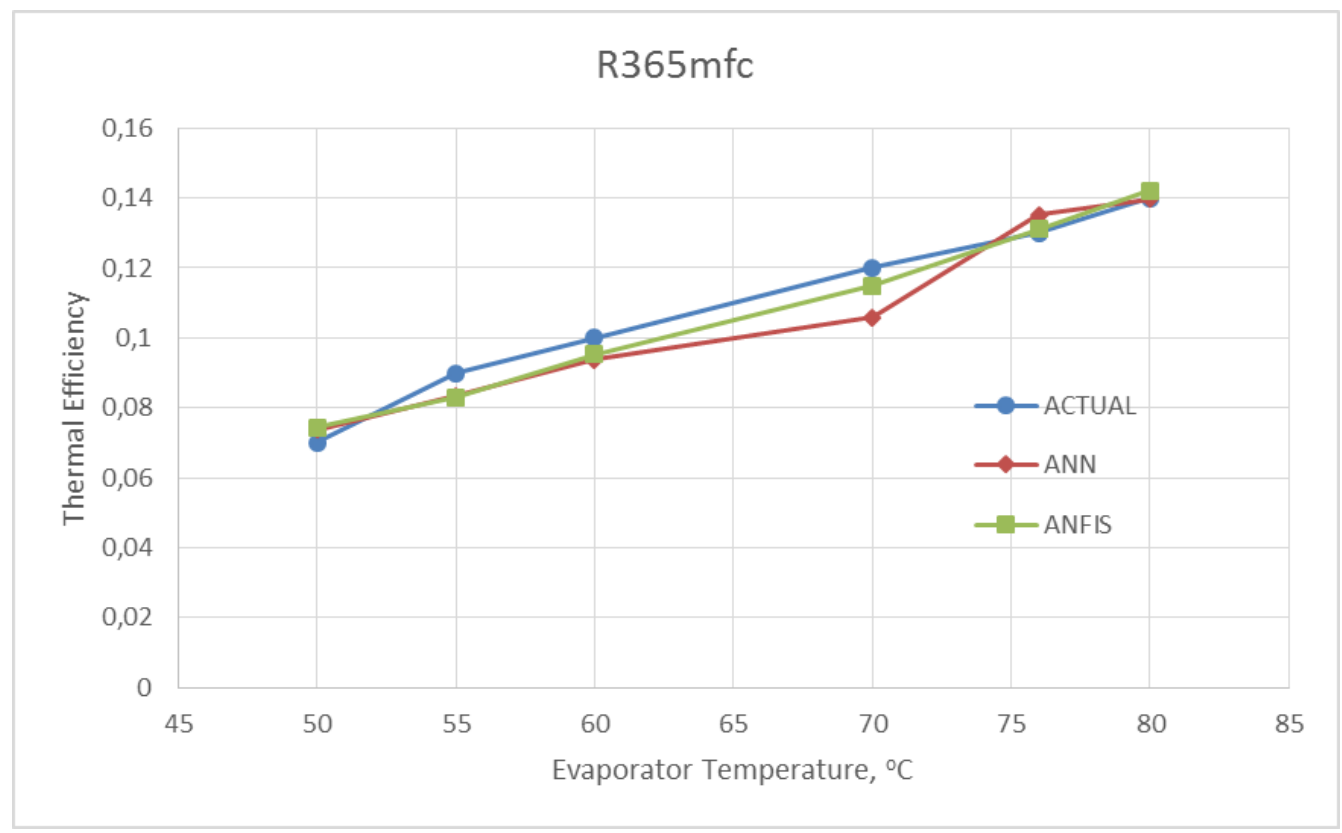

Fig. 3. Comparison of actual, ANN and ANFIS thermal efficiency values for different evaporator temperature of ORC system operating with R365-mfc

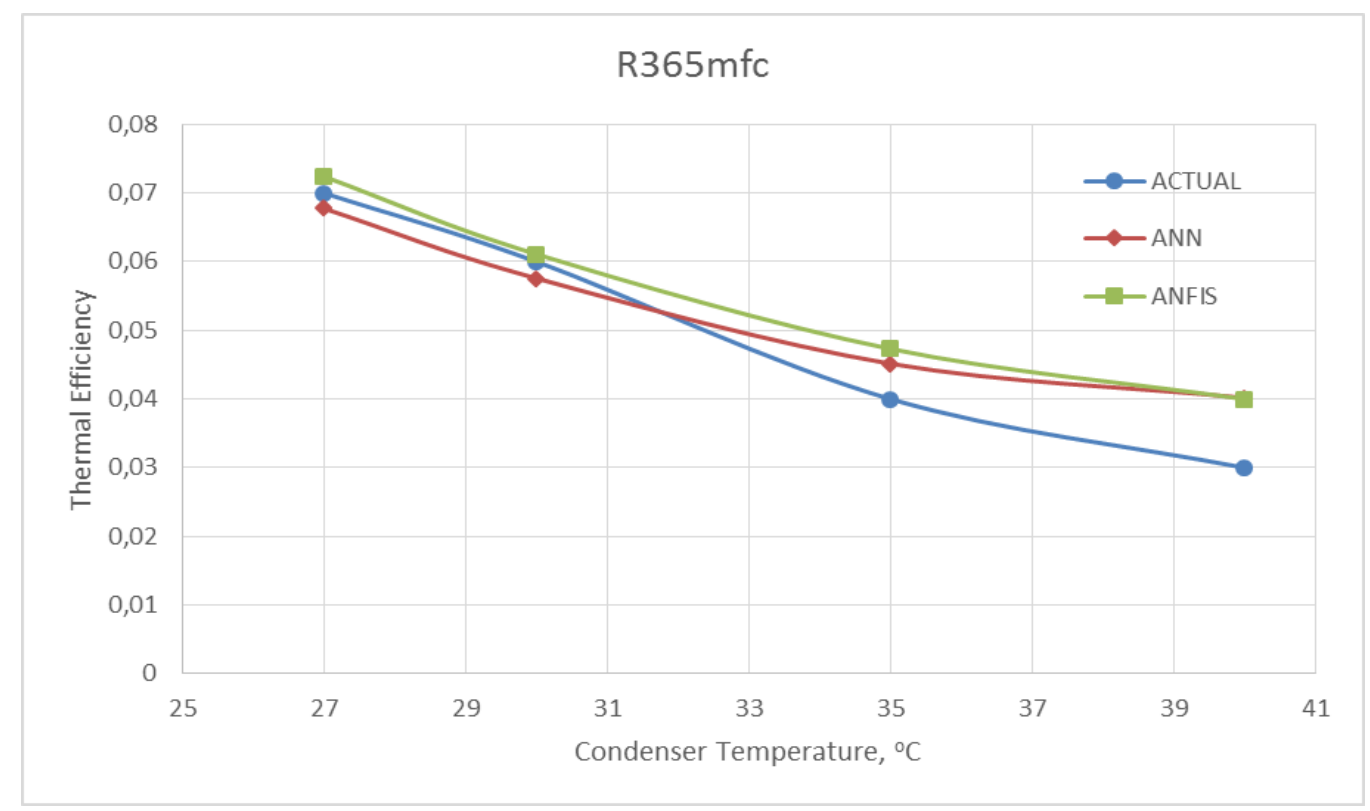

Fig. 4. Comparison of actual, ANN and ANFIS thermal efficiency values for different condenser temperature of ORC system operating with R365-mfc 


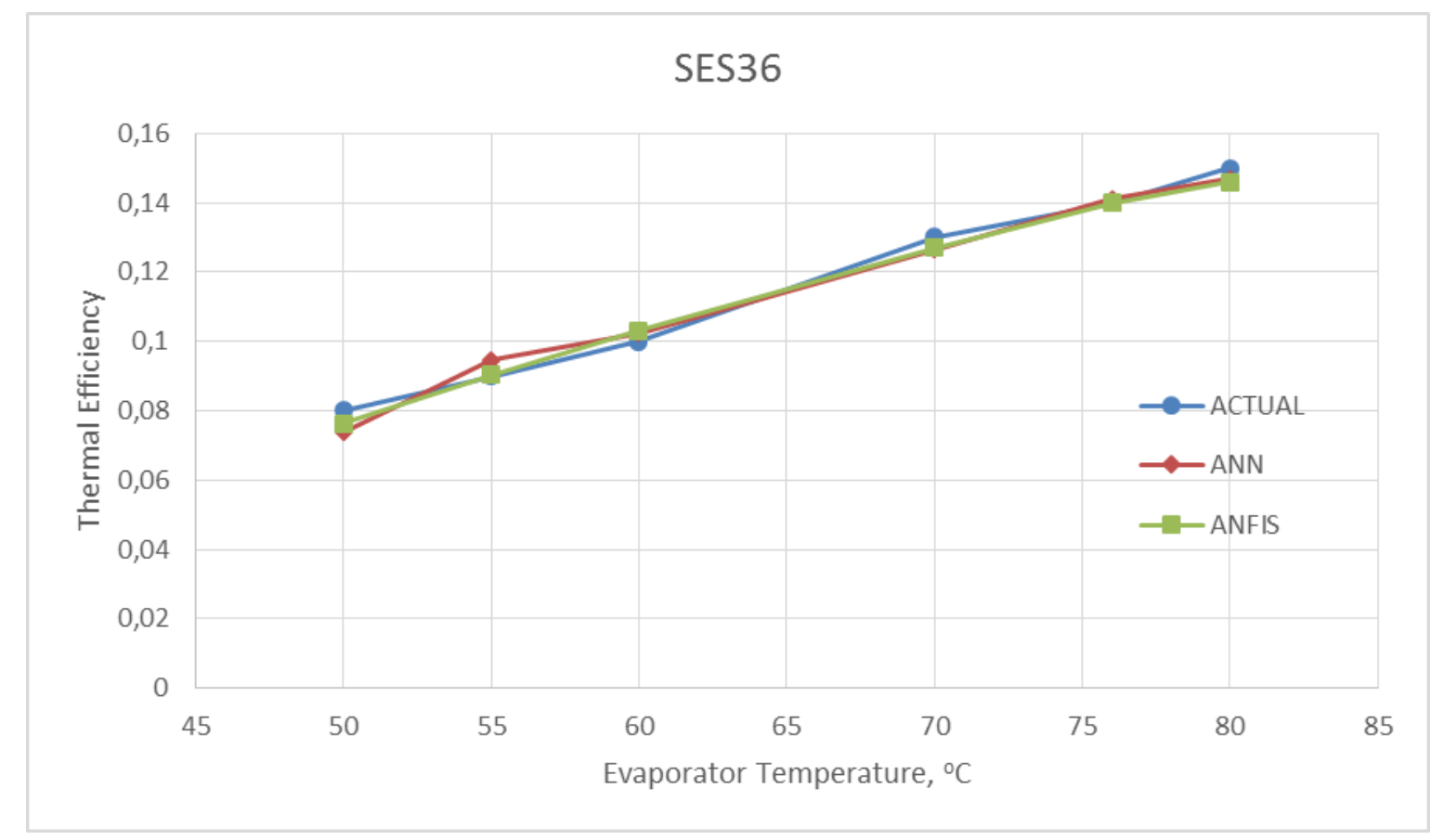

Fig. 5. Comparison of actual, ANN and ANFIS thermal efficiency values for different evaporator temperature of ORC system operating with SES36

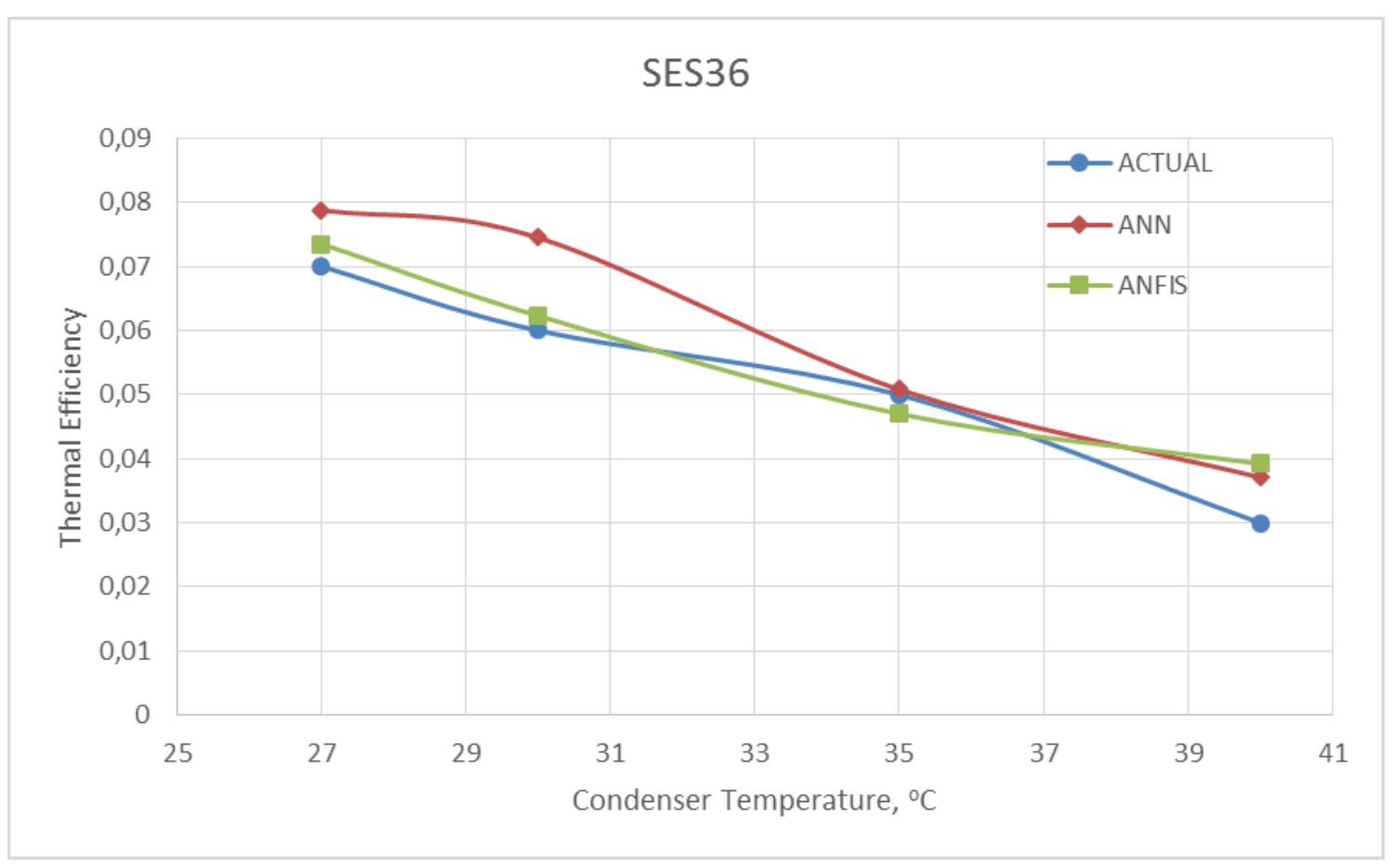

Fig. 6. Comparison of actual, ANN and ANFIS thermal efficiency values for different condenser temperature of ORC system operating with SES36 


\section{Conclusion}

Thermal efficiency values Organic Rankine systems depend on fairly the thermodynamic properties of working fluids. The thermodynamic properties of working fluids were presented in the literature as restricted data. In this study, the thermal efficiency values of Organic Rankine system estimated depending on the condenser temperature and the evaporator temperatures values by adaptive network fuzzy interference system (ANFIS) and artificial neural networks system (ANN). Estimated values are compared with actual values. The $\mathrm{R}^{2}$ values are determined 0.98 and 0.99 by ANFIS and ANN model respectively for ORC fluid of SES36. The $\mathrm{R}^{2}$-values are determined 0.97 and 0.98 by ANFIS and ANN model respectively for ORC fluid of $\mathrm{R} 365-\mathrm{mfc}$. The obtained $\mathrm{R}^{2}$ value for values can be considered as very satisfactory. The thermal efficiency values of ORC system operating with fluids of SES36 and R365-mfc can estimate ANN and ANFIS models. The results from the ANFIS and ANN models can assist for design of ORC systems. Therefore, the use of these technologies will save effort and time in the engineering process of systems.

\section{Notations}

$\begin{array}{ll}\text { GWP } & \text { Global warming potential (\% by weight) } \\ \text { ODP } & \text { Ozone depletion potential (\% by weight) } \\ \text { IPCC } & \text { Intergovernmental Panel on Climate Change } \\ \text { ORC } & \text { Organic Rankine cycle } \\ \text { ANN } & \text { Artificial Neural Networks } \\ \text { ANFIS } & \text { Adaptive network-based fuzzy inference system } \\ \text { RMS } & \text { Root mean square } \\ \text { R }^{2} & \text { Coefficient of multiple determination } \\ \text { cov } & \text { Coefficient of variation value } \\ \eta & \text { thermal efficiency }\end{array}$

\section{References}

[1] Roy, J.P., Mishra, M.K., Misra, A., Performance analysis of an Organic Rankine Cycle with superheating under different heat source temperature conditions. Applied Energy, 88(9), 2995-3004, 2011.

[2] Zhang, X., He, M., Wang, J., A new method used to evaluate organic working fluids. Energy, 67, 363-369, 2014.

[3] Solkane, Solkane Refrigerant Software. Germany.

[4] Lemmon, E.W., Span, R., Thermodynamic Properties of R-227ea, R-365mfc, R-115, and R-13I1. Journal of Chemical \& Engineering Data, 60(12), 3745-3758, 2015.

[5] Atakan, B., Siddiqi, M.A., Investigation of the criteria for fluid selection in Rankine cycles for waste heat recovery. International Journal of Thermodynamics, 14(3), 2011.

[6] Schenk, H., Evaluation of ORC processes and their implementationin solar thermal DSG plants, in Ingegneria Energetica. 2013, Milano.

[7] Wang, E.H., Zhang, H.G., Fan, B.Y., Ouyang, M.G., Zhao, Y., Mu, Q.H., Study of working fluid selection of organic Rankine cycle (ORC) for engine waste heat recovery. Energy, 36(5), 3406-3418, 2011.

[8] Wang, J., Yan, Z., Wang, M., Ma, S., Dai, Y., Thermodynamic analysis and optimization of an (organic Rankine cycle) ORC using low grade heat source. Energy, 49, 356-365, 2013. 
[9] Kosmadakis, G., Manolakos, D., Papadakis, G., Experimental investigation of a lowtemperature Organic Rankine Cycle (ORC) engine under variable heat input operating at both subcritical and supercritical conditions. Applied Thermal Engineering, 92, 1-7, 2016.

[10] Braimakis, K., Preißinger, M., Brüggemann, D., Karellas, S., Panopoulos, K., Low grade waste heat recovery with subcritical and supercritical Organic Rankine Cycle based on natural refrigerants and their binary mixtures. Energy, 88, 80-92, 2015.

[11] Yılmaz, F., Selbaş, R., Şahin, A.Ş., Efficiency analysis of organic Rankine cycle with internal heat exchanger using neural network. Heat and Mass Transfer, 52(2), 351-359, 2015.

[12] Kim, D.K., Lee, J.S., Kim, J., Kim, M.S., Kim, M.S., Parametric study and performance evaluation of an organic Rankine cycle (ORC) system using low-grade heat at temperatures below $80^{\circ} \mathrm{C}$. Applied Energy, 189, 55-65, 2017.

[13] Li, J., Liu, Q., Duan, Y., Yang, Z., Performance analysis of organic Rankine cycles using R600/R601a mixtures with liquid-separated condensation. Applied Energy, 190, 376-389, 2017.

[14] Zhang, M.-G., Zhao, L.-J., Xiong, Z., Performance evaluation of organic Rankine cycle systems utilizing low grade energy at different temperature. Energy, 127, 397-407, 2017.

[15] Javanshir, A., Sarunac, N., Thermodynamic analysis of a simple Organic Rankine Cycle. Energy, 118, 85-96, 2017.

[16] Kilıç, B., Optimisation of refrigeration system with two-stage and intercooler using fuzzy logic and genetic algorithm. International Journal Of Engineering \& Applied Sciences, 9(1), 42-42, 2017.

[17] Köse, E., Mühürcü, A., The control of non-linear chaotic system including noise using genetic based algorithm. International Journal of Engineering \& Applied Sciences, 8(3), 49$57,2016$.

[18] Kilıç, B., Alternative approach for thermal analysis of transcritical $\mathrm{CO}_{2}$ one-stage vapor compression cycles. International Journal of Engineering \& Applied Sciences, 8(1), 1-6, 2016.

[19] Şahin, A.Ş., Köse, İ.İ., Selbaş, R., Comparative analysis of neural network and neurofuzzy system for thermodynamic properties of refrigerants. Applied Artificial Intelligence, 26(7), 662-672, 2012.

[20] Ertunc, H.M., Hosoz, M., Artificial neural network analysis of a refrigeration system with an evaporative condenser. Applied Thermal Engineering, 26(5-6), 627-635, 2006.

[21] Kalogirou, S.A., Bojic, M., Artificial neural networks for the prediction of the energy consumption of a passive solar building. Energy, 25, 479-491, 2000.

[22] Shojaeefard, M.H., Zare, J., Tabatabaei, A., Mohammadbeigi, H., Evaluating different types of artificial neural network structures for performance prediction of compact heat exchanger. Neural Computing and Applications, 2016.

[23] Li, H., Tang, X., Wang, R., Lin, F., Liu, Z., Cheng, K., Comparative study on theoretical and machine learning methods for acquiring compressed liquid densities of 1,1,1,2,3,3,3Heptafluoropropane (R227ea) via song and mason equation, support vector machine, and artificial neural networks. Applied Sciences, 6(1), 25, 2016.

[24] Mago, P.J., Chamra, L.M., Somayaji, C., Performance analysis of different working fluids for use in organic Rankine cycles. Proceedings of the Institution of Mechanical Engineers, Part A: Journal of Power and Energy, 221(3), 255-263, 2007. 